\title{
Tata laksana pemotongan kuku pada sapi perah
}

\author{
Hinarno $^{1}$, Henny Endah Anggraeni ${ }^{1, *}$, Fathul Bari $^{2}$, Asep Suwandi ${ }^{2}$, Iyus Setiawan ${ }^{2}$, Rukmana $^{2}$ \\ ${ }^{1}$ Program Keahlian Paramedik Veteriner Program Diploma, Institut Pertanian Bogor, Bogor \\ ${ }^{2}$ Koperasi Peternakan Sapi Bandung Utara (KPSBU) Lembang, Bandung
}

ABSTRAK: Hoof trimming aims to restore normal hoof position, cleaning up dirts at slit hoof, avoiding lameness, facilitate early detection of laminitis and infection. This final report is purpose to explain the hoof treatment and trimming in dairy cows at Koperasi Peternakan Sapi Bandung Utara (KPSBU) Lembang West Java. Primary data obtained discuss with interviewees and join activities of hoof trimming and treatment such as preparing equipment, handling dairy cows, and hoof trimming implementation. Thus secondary data supported by study literature. Hoof trimming in dairy cows at KPSBU Lembang is carried out every 4-6 months. First, farmer should report hoof trimming implantation to officer of health. Officer prepared hoof trimming equipments. Dairy cows were handled before hoof trimming began. Hoof trimming done in a standing position cows starting from the axial and abaxial wall then continued at the sole. Hoof trimming implementation for avoiding hoof infection which disserves dairy cow production.

Keywords:

KPSBU Lembang, hoof, dairy cows, hoof trimming

\section{- PENDAHULUAN}

Kegiatan pemotongan kuku pada sapi bertujuan untuk mengembalikan posisi normal kuku, membersihkan kotoran pada celah kuku, menghindari pincang, mempermudah deteksi dini laminitis dan kemungkinan terjadinya infeksi pada kuku (Sudono 2003). Kuku harus mendapat perhatian terutama pada ternak yang selalu berada di dalam kandang. Raven (1992) menyatakan bahwa lingkungan yang lembab dan kotor akan mempermudah timbulnya luka pada interdigiti yang akan menyebabkan masuknya kuman. Kuku sapi yang tidak dipotong merupakan faktor penyebab terjadinya penyakit pada kuku. Kuku yang panjang juga dapat menyebabkan kelainan pada bagian kaki. Menurut Greenough (1996) Setiap bagian kuku sangat penting untuk menunjang peforma dari hewan tersebut, sehingga sekecil apapun gangguan yang dialami oleh bagian tertentu akan memengaruhi kesehatan hewan.

Pemotongan kuku berpengaruh terhadap kejadian footrot dan cukup bermakna, artinya kalau kuku tidak pernah dipotong maka kejadian footrot akan semakin besar (Raven 1992). Secara umum, kuku kaki depan lebih lebar dan bidang tumpu cenderung bulat dibandingkan kuku kaki belakang yang lebih sempit dengan bidang tumpu lebih oval. Kuku kaki depan sapi selain menopang badan juga sebagai peredam getaran saat berjalan (Ramey 1995 Draper and Houghton 2000).

Tujuan penulisan ini adalah menjelaskan cara perawatan dan pemotongan kuku pada kaki sapi perah melalui studi kasus di Koperasi Peternakan Sapi Bandung Utara (KPSBU) Lembang Jawa Barat.

\section{- BAHAN DAN METODE}

Pengamatan dan pengambilan data dilakukan di KPSBU Lembang, Komplek Pasar Panorama, Kecamatan Lembang, Kabupaten Bandung Barat, Provinsi Jawa Barat. Data primer didapatkan dengan melakukan tanya jawab dengan narasumber terkait dalam proses perawatan dan pemotongan kuku sapi. Data sekunder merupakan data-data pendukung yang dikumpulkan dari berbagai sumber hasil studi kepustakaan, yaitu melalui buku, jurnal, dan data pemotongan kuku di KPSBU Lembang.

\section{- HASIL DAN PEMBAHASAN}

KPSBU Lembang menerapkan perawatan kuku induk sapi setiap 4-6 bulan sekali. Pemotongan dan perawatan kuku dilaksanakan sebelum kuku sapi terlalu panjang agar tidak terjadi kelainan dan kerusakan pada kuku induk sapi. Peternak memeriksa kuku pada saat pemerahan pagi, kemudian melaporkan kepada Petugas Administrasi Daerah (PAD) di Tempat Pengumpulan Susu (TPS). Setelah itu, PAD melaporkan laporan dari peternak kepada Petugas Potong Kuku KPSBU. Persiapan hewan dilakukan sesaat sebelum dilakukan pemotongan kuku. Petugas potong kuku melakukan pemeriksaan secara inspeksi. Ternak yang terlihat memiliki kuku panjang langsung dilakukan pemotongan kuku. Proses pemotongan kuku di KPSBU dilakukan dengan posisi sapi dalam kondisi berdiri karena

Diterima: 08-11-2017 | Direvisi: 06-12-2017 | Disetujui: 17-01-2018

(C) 2018 CC-BY-SA. Ini adalah artikel Open Access yang didistribusikan berdasarkan ketentuan dari Creative Commons Attribution ShareAlike 4.0 International License (https://creativecommons.org/licenses/by-sa/4.0/). 
jumlah petugas potong kuku sangat terbatas.

Alat-alat yang digunakan adalah pisau, palu, kikir, dan rennet. Rennet digunakan untuk merapikan kaki bagian sole yang menebal (Williamson and Payne 1993). Pemotongan pada bagian axial wall dan abaxial wall dilakukan terlebih dahulu pada kaki kanan depan, setelah itu kaki kanan belakang, kaki kiri belakang, dan terakhir kaki kiri depan atau sebaliknya menggunakan pisau seperti pada Gambar 1. Pemotongan kuku sapi dilakukan sampai batas white line.
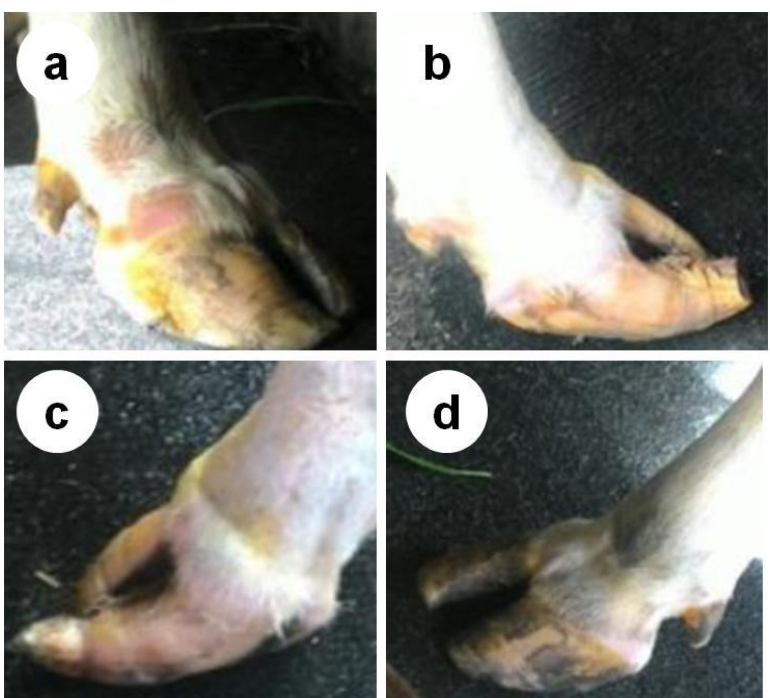

Gambar 1. Skema alur proses pemotongan kuku kaki sapi: (a) Kaki kanan depan, (b) Kaki kanan belakang, (c) Kaki kiri belakang, (d) Kaki kiri depan

Pemotongan pada bagian sole kaki sapi menggunakan rennet dengan cara menggangkat kaki sapi satu persatu dengan arah sama seperti pemotongan kuku bagian axial wall dan abaxial wall. Pemotongan pada bagian sole dilakukan secara hati-hati agar tidak terlalu dalam dan sampai melukai pembuluh darah (Gambar 2).
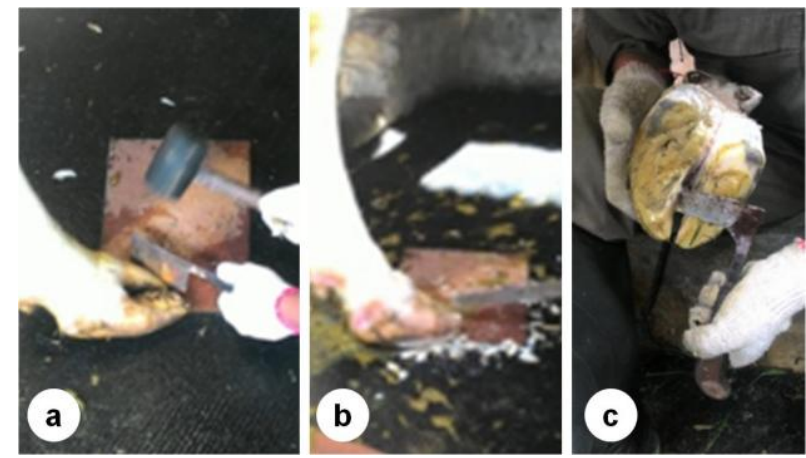

Gambar 2. Proses pemotongan (a), pengikiran (b), dan pemotongan kuku kaki sapi pada bagian sole (c).

Pemotongan pada bagian sole dilakukan secara hati-hati agar tidak terlalu dalam dan sampai melukai pembuluh darah yang terdapat pada bagian kaki sapi. Hasil kuku yang telah dirapikan dapat dilihat pada Gambar 3.

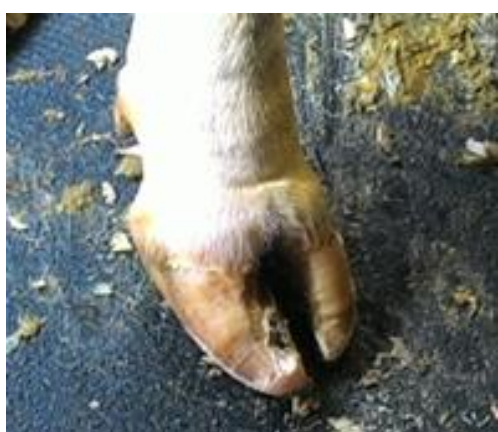

Gambar 3 Kuku sapi yang telah dirapikan

Hal-hal yang memengaruhi kesehatan kuku adalah sistem pemeliharaan, alas kandang, kebersihan kandang, pakan, dan program pemotongan kuku. Menurut AAK 1995, pemotongan kuku sapi dapat dilakukan dengan merobohkan sapi terlebih dahulu menggunakan tali, kandang jepit, atau menambatkan kaki sapi pada tiang. Proses pemotongan kuku sapi dengan cara tersebut memerlukan minimal 3-4 petugas kesehatan hewan. Kemudian kuku sapi dipotong menggunakan pisau potong kuku sapi (kame gata) atau menggunakan gerinda tangan.

\section{- SIMPULAN}

Pemotongan kuku pada induk sapi di KPSBU Lembang telah dilakukan sesuai dengan rekomendasi instansi pemerintah yaitu dengan jangka waktu 4-6 bulan sekali. Prosedur pemotongan kuku di KPSBU diawali dengan pelaporan oleh peternak kepada petugas. Pemotongan kuku dilakukan dalam posisi sapi berdiri diawali dari bagian axial dan abaxial wall kemudian dilanjutkan di bagian sole.

\section{- INFORMASI PENULIS}

Penulis untuk Korespondensi

*HEA: henny.ea12@gmail.com

Program Keahlian Paramedik Veteriner,

Program Diploma, Institut Pertanian Bogor,

Kampus IPB Cilibende J1 Kumbang No 14 Bogor 16151

\section{- PUSTAKA ACUAN}

AAK. 1995. Petunjuk praktis beternak sapi perah. Yogyakarta: Penerbit Kanisius

Draper J, Houghton K. 2000. The complete encyclopedia of the horse: a comprehensive guide to breeds and horse and pony care. United Kingdom: Southwater.

Greenough, Paul R, Laverne M. 1996. Zinpro Corporation's illustrated handbook on cattle lameness. Journal of the South African Veterinary Association. 67(1): 7-7

Ramey DW. 1995. Horse feather: fact versus myths about your horse's health. USA: Macmillan Company

Raven TE. 1992. Cattle footcare and claw trimming. United Kingdom: Farming Press Books. p3-125.

Sudono A, Rosdiana RF, Setiawan BS. 2003. Beternak sapi perah secara intensif. Jakarta: Agromedia Pustaka.

Williamson G, Payne WJA. 1993. Pengantar peternakan di daerah tropis. Gadjah Mada University Press. Yogyakarta. 